\title{
Expression of extracellular matrix metalloproteinase inducer and matrix metalloproteinases during mouse embryonic development
}

\author{
Li Chen ${ }^{1}$, Masaaki Nakai ${ }^{1,2}$, Robert J Belton Jr ${ }^{1}$ and Romana A Nowak ${ }^{1}$ \\ ${ }^{1}$ Department of Animal Sciences, University of Illinois, Urbana, Illinois 61801, USA and ${ }^{2}$ Chemistry and Metabolism, \\ Tokyo Metropolitan Institute for Neuroscience, Fuchu, Tokyo 183-8526, Japan
}

Correspondence should be addressed to R A Nowak; Email: ranowak@uiuc.edu

\begin{abstract}
Mouse embryo implantation is a highly invasive and controlled process that involves remodeling and degradation of the extracellular matrix of the uterus. Matrix metalloproteinases (MMPs) are the main proteinases facilitating this process. Extracellular matrix metalloproteinase inducer (EMMPRIN) can stimulate the production of MMPs and is required for successful implantation in the mouse. The aims of the present study were to examine the expression profiles of mRNA and proteins for EMMPRIN and MMPs in the developing mouse embryo in vitro, and to study whether EMMPRIN protein induces the production of MMPs by mouse blastocysts. EMMPRIN mRNA, detected by RT-PCR, was present at all stages of embryo development from the one-cell to the blastocyst outgrowth. EMMPRIN protein, observed by confocal microscopy, was present on the cell surface at the same stages of development as was the mRNA. Of seven MMPs studied, murine collagenase-like A (Mcol-A), murine collagenaselike B (Mcol-B) and gelatinase A (MMP-2) mRNAs were detected only in blastocyst outgrowths by RT-PCR. Gelatinase B (MMP-9) mRNA was detected both in expanded blastocysts and blastocyst outgrowths. MMP-2 and -9 proteins were detected in the cytoplasm of outgrowing trophoblast cells. Collagenase-2 (MMP-8), collagenase-3 (MMP-13), or stromelysin-1 (MMP-3) mRNAs were not present at any stage of pre- or peri-implantation mouse embryo development. Quantitative RT-PCR analyses showed that recombinant EMMPRIN protein did not stimulate MMP-2 or -9 expression by mouse blastocyst outgrowths. These data suggest that EMMPRIN may regulate physiological functions other than MMP production by mouse embryos during implantation.

Reproduction (2007) 133 405-414
\end{abstract}

\section{Introduction}

Mouse embryo implantation is a complex process that involves the carefully coordinated expression of a number of molecules including steroid hormones, growth factors, metalloproteinases (MMPs), and cytokines (Paria et al. 2002). Extracellular matrix metalloproteinase inducer (EMMPRIN) is one of these molecules. EMMPRIN is a highly glycosylated transmembrane protein with two immunoglobulin-like domains. EMMPRIN plays an essential role in implantation because most EMMPRIN null mutant embryos are lost at the time of implantation (Igakura et al. 1998).

EMMPRIN expression is increased in tumor tissues and this increase in EMMPRIN is positively correlated with the extent of tumor invasion (Zucker et al. 2001, Kanekura et al. 2002, Yang et al. 2003). One known function of EMMPRIN is to stimulate fibroblasts to produce MMPs that digest extracellular matrix (ECM; Kataoka et al. 1993, Guo et al. 1998, Lim et al. 1998,
Sameshima et al. 2000, Li et al. 2001, Sun \& Hemler 2001, Zucker et al. 2001). Both EMMPRIN purified from tumor cells and recombinant EMMPRIN have been shown to induce the expression of interstitial collagenase (MMP-1), stromelysin 1 (MMP-3), gelatinase $\mathrm{A}$ (MMP-2), and membrane type 1- and type 2-MMPs (MT1 - and MT2-MMP) by fibroblasts (Kataoka et al. 1993, Sameshima et al. 2000, Li et al. 2001, Sun \& Hemler 2001). Studies by Zucker et al. (2001) demonstrated that EMMPRIN expressed by tumor cells stimulated peri-tumoral fibroblasts to produce high levels of MMPs, which, in turn, degraded ECM and facilitated tumor invasion.

Mouse embryo implantation is an invasive process accompanied by extensive degradation and remodeling of the endometrium, in particular the ECM of the stroma. Trophoblast cells penetrate the basement membrane of uterine luminal epithelial cells and further invade the underlying decidual stroma. Embryo implantation is so similar to the process of tumor invasion that trophoblast 
cells are sometimes called pseudomalignant cells (Cross et al. 1994). Trophoblast giant cells can degrade ECM and spread outward from the inner cell mass. The extent of ECM turnover and degradation is significant as the embryo invades into the uterus. Previous studies have reported that MMP-9 and -2 are expressed by peri-implantation mouse blastocysts. However, a comprehensive study of MMP expression during preimplantation mouse embryo development has not been documented. The goals of our present study were twofold. The first aim was to determine whether and when EMMPRIN and the following MMPs were expressed by mouse embryos: murine collagenase-like A (Mcol-A), murine collagenase-like B (Mcol-B), collagenase 2 (MMP-8), collagenase 3 (MMP-13), gelatinase A (MMP-2), gelatinase B (MMP-9), and stromelysin 1 (MMP-3). Our second goal was to determine whether recombinant EMMPRIN protein is able to enhance MMP-2 and -9 production by mouse blastocysts. In this study, we demonstrated that EMMPRIN mRNA and protein were expressed by mouse embryos at all stages of development. Of seven MMPs studied, only Mcol-A, Mcol-B, MMP-2, and -9 were expressed by implanting blastocysts. Recombinant EMMPRIN did not stimulate MMP-2 or -9 mRNA or protein expression by blastocyst outgrowths.

\section{Materials and Methods}

\section{Animals}

Animals used in this work were maintained in accordance with the guidelines of the Institutional Animal Care and Use Committee at the University of Illinois-Urbana. All embryos used were collected from outbred CF1 female mice (Crl; CF1 BR, 6-8-week old, Harlan Sprague-Dawley, Indianapolis, IN, USA) by mating with hybrid BDF males (B6D2F1/CrlBR; Harlan Sprague-Dawley). All the animals were maintained on a 12L:12D cycle with food and water ad libitum. Female mice were superovulated by an injection of $5 \mathrm{IU}$ pregnant mare serum gonadotrophin (Sigma) i.p. at $1400 \mathrm{~h}$, followed by an injection of 5 IU hCG (Sigma) $48 \mathrm{~h}$ later. Females were caged individually with a male overnight after hCG injection and were checked for a vaginal plug on the following morning. When the vaginal plug was present, females were assumed to be at day 1 of pregnancy.

\section{Generation and purification of recombinant human EMMPRIN}

The extracellular domain of human EMMPRIN was amplified from cDNA by high-fidelity PCR and ligated into Bsal-linearized pASK_IBA44 vector I (IBA, Göttingen, Germany). The plasmid construct (IBA44-rBSG) was transformed into DH5alpha Escherichia coli and purified using the Eppendorf Perfect Prep Maxi kit according to the manufacturer's specifications. DNA sequencing of the construct was performed at the University of Illinois Biotechnology Center.

For recombinant protein expression, the IBA44-rBSG construct was transformed into the BL21-RP CodonPlus strain of E. coli. Cultures were grown at $37{ }^{\circ} \mathrm{C}, 250$ r.p.m. for $6 \mathrm{~h}$ and then diluted into super optimal broth/ catabolic repression (SOC) containing chloramphenicol and ampicillin and grown at $25{ }^{\circ} \mathrm{C}$, 250 r.p.m. for 12-14 h. The overnight cultures were diluted into SOC containing ampicillin, and protein expression induced with the addition of $0.2 \mu \mathrm{g} / \mathrm{ml}$ anhydrotetracycline. After $6 \mathrm{~h}$ induction, the cells were harvested by centrifugation at $4500 \mathrm{~g}$ for $12 \mathrm{~min}$ at $4{ }^{\circ} \mathrm{C}$, and resuspended in $80 \mathrm{ml} / \mathrm{g}$ wet weight of ice cold sucrose buffer $(20 \% \mathrm{w} / \mathrm{v}$ sucrose, $30 \mathrm{mM}$ Tris, $\mathrm{pH}$ 8). EDTA was added drop-wise to a final $1 \mathrm{mM}$ concentration and the cells were incubated on ice for $10 \mathrm{~min}$. The cell suspension was centrifuged at $8000 \mathrm{~g}$ for $20 \mathrm{~min}$ at $4{ }^{\circ} \mathrm{C}$. Cells were gently resuspended in cold $5 \mathrm{mMMgSO}_{4}, 5 \mathrm{mM}$ Tris, $\mathrm{pH} 7.4$ and incubated on ice for $10 \mathrm{~min}$. The osmotic shock lysate (OSL) was isolated by centrifugation of the sample at $8000 \mathrm{~g}$ for $20 \mathrm{~min}$ at $4{ }^{\circ} \mathrm{C}$ to pellet the cells, and the OSL was filtered through a $0.22 \mu \mathrm{m}$ cellulose acetate filter to remove any remaining cellular debris.

Prior to protein purification, the OSL was concentrated 250-fold using $10 \mathrm{kDa}$ molecular weight cutoff (MWCO) Millipore Amicon Ultra centrifugal filters and dialyzed into Wash Buffer (300 mM NaCl, $50 \mathrm{mM} \mathrm{NaH}_{2} \mathrm{PO}_{4}, \mathrm{pH}$ 8). The OSL from $1 \mathrm{I}$ of culture was incubated with $1 \mathrm{ml}$ of Talon Metal Affinity Beads for 90 min at $4{ }^{\circ} \mathrm{C}$. The bound protein was washed with 30 bed volumes of Wash Buffer, followed by 10 bed volumes of Wash Buffer containing $5 \mathrm{mM}$ imidazole. The recombinant protein was eluted with 10 bed volumes of Wash Buffer containing $200 \mathrm{mM}$ imidazole. The eluted protein was dialyzed into PBS, resolved by SDS-PAGE and analyzed by Coomassie staining and immunoblotting with an anti-EMMPRIN polyclonal antibody (R\&D systems, Minneapolis, MN, USA).

\section{Embryo/oocyte collection and culture}

One-cell and two-cell embryos were flushed from oviducts on days 1 and 2 respectively, while embryos at the later stages were cultured from two-cell embryos in vitro. Embryos were collected using Hepes-buffered KSOM (high potassium simplex optimized medium) and cultured in $50 \mu \mathrm{l}$ of KSOM containing essential and nonessential amino acids (Gibco) under mineral oil in an atmosphere of $5 \% \mathrm{CO}_{2}, 5 \% \mathrm{O}_{2}$ and $90 \% \mathrm{~N}_{2}$ at $37{ }^{\circ} \mathrm{C}$, as previously described (Nowak et al. 1999). Blastocysts were transferred to 96-well plates coated with $200 \mu \mathrm{g} / \mathrm{ml}$ fibronectin (Becton Dickinson, Bedford, MA, USA) in F-10 medium containing $10 \%$ fetal bovine serum (FBS; Biowhittaker, Walkerville, MD, USA) after hatching. Blastocysts attached and grew out on the bottom of the 
wells by the next day. The culture medium was then switched to fresh F-10 medium without FBS. After $24 \mathrm{~h}$ of serum starvation, blastocyst outgrowths were treated with $10 \mu \mathrm{g} / \mathrm{ml}$ recombinant human EMMPRIN protein for $24 \mathrm{~h}$. The conditioned medium was harvested for zymography analysis and RNA was isolated for quantitative RT-PCR analysis for MMP-2 and -9.

\section{Mouse uterine stromal cell culture}

Mouse uterine stromal cells were isolated from day 4 pseudopregnant CD-1 mice, as previously described (Daikoku et al. 2005). Stromal cells were cultured in DMEM/F12 medium containing 10\% FBS. Once cells reached $70-80 \%$ confluence, the medium was switched to fresh serum-free DMEM/F12 medium. After $24 \mathrm{~h}$ of serum starvation, cells were treated with 1,10 , or $100 \mathrm{ng} / \mathrm{ml}$ human recombinant EMMPRIN protein for $24 \mathrm{~h}$. Cells without any treatment served as a control. Conditioned media were concentrated 50-fold with Amicon Ultra-4 10 kDa centrifugal filters (Millipore, Billercia, MA, USA) and subjected to immunoblotting for MMP-3 and -9.

\section{Immunoblotting}

Fifteen microliters of concentrated media were denatured in Laemmli sample buffer at $95{ }^{\circ} \mathrm{C}$ for $5 \mathrm{~min}$. Proteins were separated by $10 \%$ SDS-PAGE gels and were transferred to nitrocellulose membranes. After blocking in $5 \%(\mathrm{w} / \mathrm{v})$ non-fat dry milk, the membranes were probed with a goat anti-human MMP-3 antibody (Santa Cruz Biotechnology, Santa Cruz, CA, USA) at a 1:400 dilution for $1 \mathrm{~h}$ and then washed three times. The membranes were then incubated with a donkey anti-goat IgG-HRP (Santa Cruz Biotechnology) at a 1:5000 dilution for $1 \mathrm{~h}$ at room temperature. The bound secondary antibody was detected using a SuperSignal West Pico substrate kit (Pierce, Rockford, IL, USA). The same procedure was performed for immunoblotting for MMP-9. A rabbit antimouse MMP-9 antibody was used at a 1:2500 dilution (Affinity Bioreagents, Golden, CA, USA) and a goat antirabbit IgG-HRP (Cell Signaling Technology, Danvers, MA, USA) was used as a secondary antibody.

For immunoblotting for human EMMPRIN, a goat antihuman EMMPRIN antibody at $2 \mu \mathrm{g} / \mathrm{ml}$ (R\&D) and a donkey anti-goat IgG-HRP (Santa Cruz Biotechnology) at a 1:5000 dilution were used as a primary and secondary antibody respectively.

\section{RNA isolation}

Total RNA was isolated from approximately 300 one-cell embryos, 150 two-cell embryos, 80 four-cell embryos, 40 eight-cell embryos, 20 morula, 10 expanded blastocysts, and 5 blastocyst outgrowths using Trizol reagent (Invitrogen). Control RNA was obtained by harvesting the whole mouse uterus at day 10.5 of gestation, homogenizing it in liquid nitrogen, and then isolating total RNA with Trizol. All steps were performed according to the manufacturer's instructions.

\section{RT-PCR}

Poly(A) RNA was reverse transcribed by (murine leukemia virus) M-MLV reverse transcriptase (Gibco) using an oligo (dT)12-18 primer to prepare cDNA according to manufacturer's instructions. The final volumes of the cDNA from different stage embryos were $20 \mu \mathrm{l}$. Two microliters of cDNA were used for each amplification reaction. The cDNA from the uterus at day 10.5 of pregnancy was used as a positive control. The sample containing distilled water instead of DNA template was used as a blank sample. Genomic DNA isolated from mouse tails by proteinase $\mathrm{K}$ was used as a genomic DNA control.

RT-PCR primers for EMMPRIN and MMPs were designed using already published gene sequences. The sequences of forward and reverse primers used for RT-PCR amplification and the expected sizes of these RT-PCR products are shown in Table 1. After an initial denaturation step of $10 \mathrm{~min}$ at $95{ }^{\circ} \mathrm{C}$, 35 cycles of denaturation at $95{ }^{\circ} \mathrm{C}$ for $1 \mathrm{~min}$, annealing at different annealing temperatures for $1 \mathrm{~min}$, and extension at $72{ }^{\circ} \mathrm{C}$ for $1 \mathrm{~min}$ were performed. A final extension step at $72{ }^{\circ} \mathrm{C}$ for $10 \mathrm{~min}$ was done in order to complete the PCR reaction. The PCR products were confirmed by DNA sequencing. RT-PCR for $\beta$-actin was also performed to confirm the integrity of embryo cDNA.

\section{Quantitative RT-PCR analysis}

Total RNA isolated from ten blastocyst outgrowths as described previously was reversed transcribed in a total volume of $20 \mu \mathrm{l} \mathrm{cDNA}$. Five microliters of cDNA were used for quantitative RT-PCR analysis for each gene. Quantitative RT-PCR analyses were performed using TaqMan Universal PCR Master Mix No AmpErase UNG (Applied Biosystems, Atlanta, GA, USA). Genes were amplified using $20 \times$ Assays-on-Demand Gene Expression Assays purchased from Applied Biosystems (sequence listed on Table 2). Quantitative PCR amplification and detection were performed in MicroAmp optical 384-well reaction plates using the $A B I 7900$ sequence detection system for 40 cycles $\left(95{ }^{\circ} \mathrm{C}\right.$ for $15 \mathrm{~s}$ and $60{ }^{\circ} \mathrm{C}$ for $1 \mathrm{~min}$ ). Relative gene mRNA levels were calculated using $\Delta \Delta \mathrm{Ct}$ method with glyceraldehyde-3-phosphate dehydrogenase $(\mathrm{GAPDH}) \mathrm{mRNA}$ as an internal control.

\section{Gelatin zymography}

Twenty microliters of conditioned medium from 40 blastocyst outgrowths either treated with $10 \mu \mathrm{g} / \mathrm{ml}$ recombinant human EMMPRIN protein or untreated 
Table 1 Sequences of the forward and reverse primers used for RT-PCR.

\begin{tabular}{|c|c|c|c|c|}
\hline Gene & Forward $\left(5^{\prime}-3^{\prime}\right)$ & Reverse $\left(5^{\prime}-3^{\prime}\right)$ & Fragment size (bp) & Annealing temperature $\left({ }^{\circ} \mathrm{C}\right)$ \\
\hline$\beta$-Actin & СТСТTССАGССТTССТTССТG & GAAGCATTTGCGGTGGACGAT & 345 & 51 \\
\hline Mcol-A & TACTCACAACAATCCTCGTTGG & CCACGTCTCATCAAGGTCATAA & 304 & 55 \\
\hline Mcol-B & TACTCACAACAATCCTCGTTGG & TAGGCCTGGCAGAAAAGCATGA & 262 & 56 \\
\hline MMP-2 & СTCTGCGTCСTGTGCTGCСTGTTG & AAAGTGAGAATCTCССССАACACC & 573 & 62 \\
\hline MMP-3 & GCTTTGAAGGTCTGGGAGGAGGTG & САGСТАTСТTССТGGGAAATССТG & 850 & 58 \\
\hline MMP-8 & TCCATTACTGATCTTCСТССА CACAC & TTGTTGATGTCTGCTTCTCССTGTAA & 431 & 58 \\
\hline MMP-9 & СTCAGAGATTCTCCGTGTCСTGTA & GACTGCCAGGAAGACACTTGGTTA & 241 & 63 \\
\hline MMP-13 & CATCCATCCCGTGACCTTAT & GCATGACTCTCACAATGCCA & 383 & 55 \\
\hline EMMPRIN & CTGAGGTCCTGGTGTTGGTT & СССССТССААСАGТАAGTCA & 530 & 57 \\
\hline
\end{tabular}

were electrophoresed under non-reducing conditions in a $10 \%$ acrylamide gel containing $1 \mathrm{mg} / \mathrm{ml}$ gelatin. After electrophoresis, gels were washed at room temperature for $1 \mathrm{~h}$ in $2.5 \%(\mathrm{v} / \mathrm{v})$ Triton X-100, $50 \mathrm{mM} \mathrm{NaCl}, 5 \mathrm{mM}$ $\mathrm{CaCl}_{2}, 50 \mathrm{mM}$ Tris- $\mathrm{HCl}, \mathrm{pH} 7.5$ and then incubated at $37{ }^{\circ} \mathrm{C}$ overnight in buffer containing $150 \mathrm{mM} \mathrm{NaCl}$, $5 \mathrm{mM} \mathrm{CaCl}_{2}, 50 \mathrm{mM}$ Tris- $\mathrm{HCl}, \mathrm{pH}$ 7.6. Gels were then stained with $0.1 \%(\mathrm{w} / \mathrm{v})$ Coomassie brilliant blue R-250 in $30 \%(\mathrm{v} / \mathrm{v})$ isopropyl alcohol, $10 \%(\mathrm{v} / \mathrm{v})$ glacial acetic acid for $60 \mathrm{~min}$, and destained in $10 \%(\mathrm{v} / \mathrm{v})$ methanol, $5 \%(\mathrm{v} / \mathrm{v})$ glacial acetic acid for $2 \mathrm{~h}$.

\section{Indirect immunofluorescent staining}

Mouse embryos were fixed in 3\% (w/v) paraformaldehyde for $30 \mathrm{~min}$ at $37{ }^{\circ} \mathrm{C}$. Fixed embryos were incubated in $0.2 \%(\mathrm{v} / \mathrm{v})$ Triton for $45 \mathrm{~min}$ at room temperature and then placed in a blocking solution ( $5 \% \mathrm{v} / \mathrm{v}$ rabbit serum, $0.1 \%$ $\mathrm{v} / \mathrm{v}$ Tween-20, $0.02 \% \mathrm{w} / \mathrm{v} \mathrm{NaN} \mathrm{N}_{3}$, PBS) overnight at $4{ }^{\circ} \mathrm{C}$. Embryo outgrowths were placed in quench solution (50 mmol glycine, $1 \% \mathrm{v} / \mathrm{v}$ rabbit serum, $0.03 \% \mathrm{v} / \mathrm{v}$ Tween-20, PBS) for $15 \mathrm{~min}$ at room temperature. Embryos were then incubated with $2 \mu \mathrm{g} / \mathrm{ml}$ goat polyclonal antibody to mouse EMMPRIN (R\&D systems) at $37{ }^{\circ} \mathrm{C}$ for $60 \mathrm{~min}$, before an incubation in fluorescein isothiocyanate (FITC)-conjugated rabbit anti-goat IgG (Sigma) for $60 \mathrm{~min}$ at $37{ }^{\circ} \mathrm{C}$. Embryos were then incubated through increasing concentration of glycerol $(2.5,5,10,20$, and $50 \% \mathrm{v} / \mathrm{v})$ for 5-10 min each to dehydrate. Nuclei were counterstained with propidium iodide (Sigma). Samples were observed using a Zeiss LSM510 confocal microscope (Zeiss, Oberkochen, Germany) and digital images were recorded and processed by a personal computer.

The same procedure was used for MMP-2 and -9 staining, with the exception of the antibodies. The primary antibodies were rabbit anti-mouse MMP-2 $(0.5 \mu \mathrm{g} / \mathrm{ml}$, Santa Cruz Biotechnology) and rabbit anti-mouse MMP-9
$(0.25 \mu \mathrm{g} / \mathrm{ml}$, Affinity BioReagent, Golden, CO, USA), while the secondary antibody was a Cy3-conjugated goat anti-rabbit IgG (Jacobson Laboratory, West Grove, PA, USA) or FITC-conjugated goat anti-rabbit IgG (Sigma). Nuclei were counterstained with propium iodide $(\mathrm{PI})$ or 4',6-diamidino-2-phenylindole dihydrochloride (DAPI).

\section{Statistical analysis}

Results are represented as mean \pm s.E. Differences between groups were examined using $t$-test. Statistical significance was set as $P<0.05$.

\section{Results}

\section{Expression of EMMPRIN mRNA and protein in pre- and peri-implantation mouse embryos}

RT-PCR for EMMPRIN showed that EMMPRIN mRNA was present at all stages of mouse embryo development from the one-cell to the blastocyst outgrowth stages (Fig. 1). The EMMPRIN amplification product for the cDNA was $530 \mathrm{bp}$, which was smaller than that for genomic DNA (Fig. 1), indicating that there was no contamination with genomic DNA in our RT-PCR reactions.

Consistent with the results of the RT-PCR, EMMPRIN protein was observed in mouse embryos at all stages of development (Fig. 2B-H). Intense immunoreactivity for EMMPRIN was observed on the surface of blastomeres. EMMPRIN was located in both inner cell mass and trophectoderm cells of blastocysts. In blastocyst outgrowths, both cells in the inner cell mass and trophoblast cells spreading out over the fibronectin matrix were positive for EMMPRIN (Fig. 2H). No immunoreactivity was detected in the absence of EMMPRIN primary antibody (Fig. 2A).

Table 2 Reference sequences used for quantitative RT-PCR.

\begin{tabular}{|c|c|c|c|}
\hline Gene & $N C B I$ gene reference & Assay ID & Reference sequence \\
\hline MMP-2 & NM_008610 & Mm00439508_m1 & GGACCTGCAGGGCGGTGGTCATAGC \\
\hline$M M P-9$ & NM_013599.2 & Mm00442991_m1 & CATCTTCCAGTACCAAGACAAAGCC \\
\hline GAPDH & NM_008084 & Mm99999915_g1 & TGAACGGATTTGGCCGTATTGGGCG \\
\hline
\end{tabular}




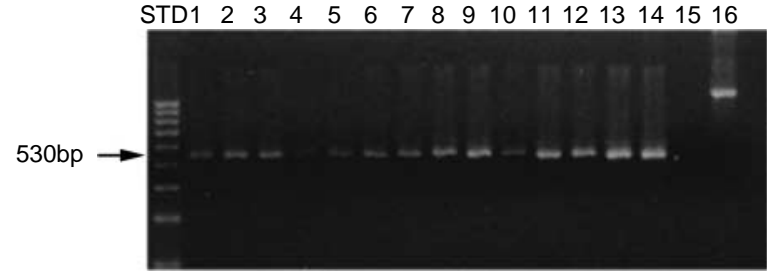

Figure 1 Transcription of EMMPRIN mRNA in developing mouse embryos. RNA from unfertilized oocytes and embryos at different stages of development was subjected to RT-PCR for EMMPRIN. STD, DNA marker; 1 , oocyte with cumulus cells; 2 , oocyte without cumulus cells; 3, one-cell embryo; 4, two-cell embryo; 5, four-cell embryo; 6 , uncompacted eight-cell embryo; 7 , compacted eight-cell embryo; 8 , morula; 9, early blastocyst; 10 , expanded blastocyst; 11 , hatching blastocyst; 12, hatched blastocyst; 13, blastocyst outgrowth for $48 \mathrm{~h} ; 14$ blastocyst outgrowth for $72 \mathrm{~h}$; 15 , no DNA template; 16 , genomic DNA

\section{Expression of mRNAs for MMPs in mouse embryos}

All cDNAs were first tested for the expression of $\beta$-actin in order to confirm the integrity of the RNA collected (Fig. 3). The mouse uterus at day 10.5 of pregnancy was used as a positive control. The results of our RT-PCR analysis showed that blastocysts undergoing outgrowth in vitro highly expressed the mRNAs for Mcol-A and -B. Single amplified bands of the expected sizes of 304 and 262 bp respectively were detected in blastocysts undergoing outgrowth for 48 and $72 \mathrm{~h}$ (Fig. 3). These amplified products were not detected at any other stage of embryo development from the one-cell to the expanded blastocyst. A weak signal for MMP-2 mRNA was only detected in blastocysts undergoing outgrowth for $72 \mathrm{~h}$ (Fig. 3). MMP-9 mRNA was detected in expanded blastocysts and blastocysts that had undergone outgrowth for 48 or $72 \mathrm{~h}$ in vitro (Fig. 3). PCR amplification products for MMP-3, -8 and, -13 were not detected at any stage of mouse pre-implantation development (Fig. 3). Only the RNA from the positive control uterine tissue at day 10.5 of pregnancy produced positive bands for all three of these MMPs.

\section{Expression of MMP-2 and -9 proteins by mouse blastocyst outgrowths}

Immunofluorescent staining showed that trophoblast cells that grew out on fibronectin matrix in vitro were the cells that expressed MMP-2 (Fig. 4) and MMP-9 (Fig. 5) proteins. MMP-2 staining was observed in the cytoplasm of trophoblast cells (Fig. 4). Intense staining of MMP-9 protein was detected in the cytoplasm of trophoblast cells, particularly in the perinuclear region (Fig. 5).

\section{Recombinant human EMMPRIN protein does not stimulate MMP-2 or -9 expression by mouse blastocyst outgrowths}

Expression of EMMPRIN mRNA and protein in the developing mouse embryo occurs at a much earlier time than the onset of MMP production, suggesting that EMMPRIN may not induce MMP expression in mouse embryos. We utilized recombinant human EMMPRIN protein to determine whether EMMPRIN stimulates MMP production by blastocysts. Recombinant EMMPRIN possessing the extracellular domain of human EMMPRIN was purified from $E$. coli engineered to target the expressed protein into the bacterial periplasm. The SDS-PAGE analysis of the protein purification fractions demonstrated that the recombinant protein was purified as an intact molecule, with the anticipated mass of $23 \mathrm{kDa}$ (Fig. 6A). Furthermore, immunoblot analysis with an anti-human EMMPRIN polyclonal antibody demonstrated that the purified protein is EMMPRIN (Fig. 6B). Preliminary experiments were performed to determine the biological activity of the recombinant EMMPRIN protein. Our results indicated that $10-100 \mathrm{ng} / \mathrm{ml}$ of recombinant human EMMPRIN protein could strongly induce MMP-3 and -9 protein expression by mouse uterine stromal cells (Fig. 6C). Quantitative RT-PCR analysis of blastocyst outgrowths treated with $10 \mu \mathrm{g} / \mathrm{ml}$ recombinant EMMPRIN protein showed no significant increase in either MMP-2 or -9
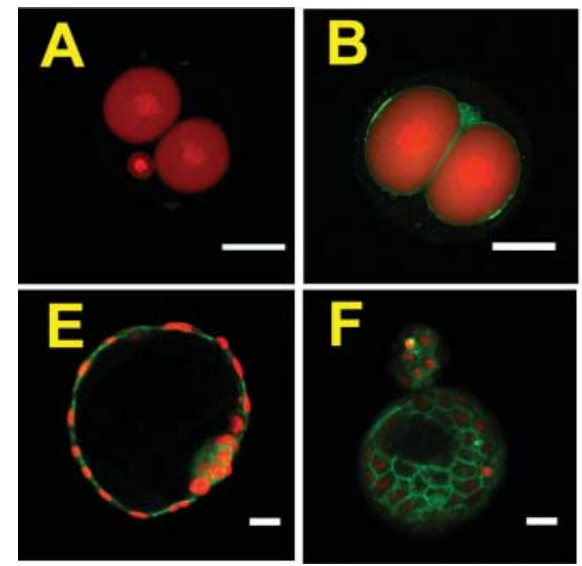
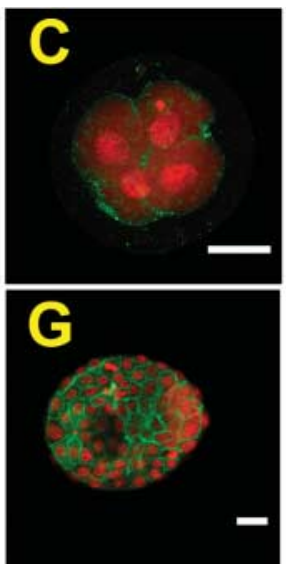

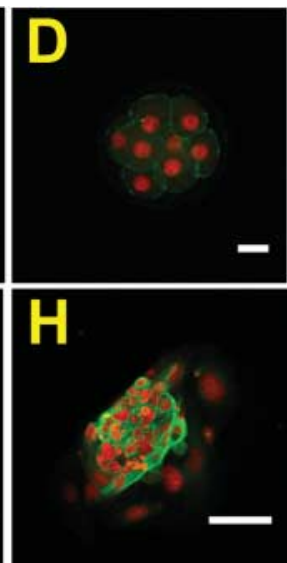

Figure 2 Expression of EMMPRIN protein in mouse pre- and peri-implantation embryos. Embryos were immunostained with goat nonspecific $\lg \mathrm{G}(\mathrm{A})$ or a goat anti-mouse EMMPRIN antibody (B-H). Intensive immunoreactivity is detected on the cell surface of the blastomeres. Photos show the two-cell embryo (A and $B)$, four-cell embryo (C), eight-cell embryo (D), expanded blastocyst (E), hatching blastocyst (F), hatched blastocyst (G), and blastocyst outgrowth $(\mathrm{H})$. Scale bars, $50 \mu \mathrm{m}$. 


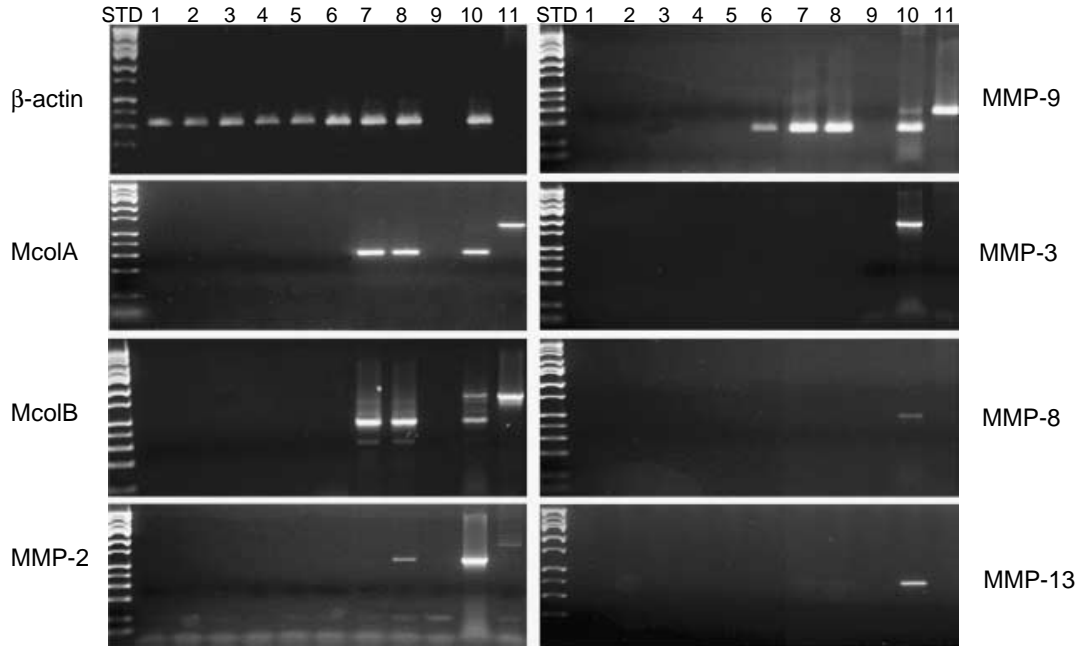

Figure 3 Transcription of MMP mRNAs in developing mouse embryos. RNA from mouse embryos at different stages was subjected to RT-PCR for $\beta$-actin, Mcol-A, Mcol-B, MMP-2, MMP-9, MMP-3, MMP-8, and MMP-13. STD, DNA marker; 1 , one-cell embryo; 2 , two-cell embryo; 3, four-cell embryo; 4, eight-cell embryo; 5, morula; 6, expanded blastocyst; 7, blastocyst outgrowth for $48 \mathrm{~h}$; 8 , blastocyst outgrowth for $72 \mathrm{~h} ; 9$, no DNA template; 10 , positive control; 11, genomic DNA.
mRNA levels (Fig. 7A). Gelatin zymography of the conditioned media from the blastocyst cultures revealed the presence of strong MMP-9 enzymatic activity that was not altered in cells treated with recombinant EMMPRIN (Fig. 7B). In contrast, both treated and untreated blastocyst cultures possessed MMP-2 activity that was too weak to be detected by zymography (Fig. 7B).

\section{Discussion}

The goals of our study were to examine the expression profiles of EMMPRIN and MMPs in mouse embryos ranging from one-cell to blastocyst outgrowth and to determine whether EMMPRIN is able to stimulate the production of MMPs by mouse blastocysts. EMMPRIN mRNA and protein were detected in all stages of mouse embryos examined. Among the seven MMPs that we studied, Mcol-A, Mcol-B, MMP-2, and -9 mRNAs were detected mainly in peri-implantation embryos; that is, blastocysts undergoing outgrowth in vitro. Consistent with previous studies, our experiments showed a great increase in the expression of MMPs during the periimplantation period, suggesting that there is a developmental regulation of these MMPs (Sharkey et al. 1996). Our results also indicate that the expression of EMMPRIN in the mouse embryo begins at the earliest stages of development, whereas the expression of MMPs is not initiated until significantly later when the embryo is preparing to implant.

In this study, we demonstrated a similar expression profile for MMP-9 mRNA by mouse embryos, as reported in previous studies (Table 3; Sharkey et al. 1996, Whiteside et al. 2001, Kim et al. 2002). Studies by Sharkey et al. (1996) demonstrated the strong expression of MMP-9 mRNA by mouse blastocyst after $24 \mathrm{~h}$ of outgrowth. Kim et al. (2002) found strong MMP-9 protein activity of blastocyst outgrowths by gelatin zymography, although they did not detect MMP-9 mRNA in blastocyst outgrowths by RT-PCR. MMP-9 is able to degrade type IV collagen of the basement membrane, fibronectin, laminin, elastin, entactin, gelatin, and proteoglycans (Curry \& Osteen 2003). The presence of MMP-9 mRNA coincides with the outgrowth of trophoblast cells from embryos. Consistent with this finding, treatment of mouse blastocyst outgrowths with MMP-9 antisense oligonucleotides results in a reduction of ECM degradation (Whiteside et al. 2001). In addition, biologically active MMP-9 protein has been identified in mouse blastocyst outgrowths using gelatin zymography and this activity was blocked by an antibody against MMP-9 (Behrendtsen et al.Herubel 1992). However, targeted deletion of the MMP-9 gene did not lead to the failure of implantation ( $\mathrm{Vu}$ et al. 1998). These data suggest that MMP-9 plays an important role in degradation of uterine stromal ECM but is not necessarily required for implantation. It is likely that mouse embryos express other proteinases that can compensate for the absence of MMP-9 in the null mutant embryo.

Mcol-A and -B are two newly identified collagenases that are structurally and functionally related to human MMP-1 (Balbin et al. 2001). Because Mcol-A and -B can degrade collagen during ECM remodeling (Balbin et al. 2001), the expression of Mcol-A and -B by periimplantation embryos may play an important role for successful implantation. An earlier study reported that the distribution of Mcol-A and -B mRNA was restricted to

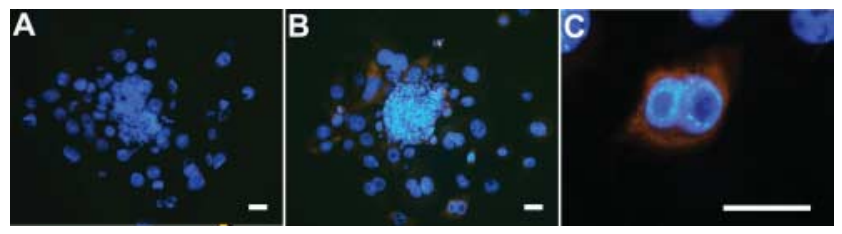

Figure 4 Expression of MMP-2 protein in mouse blastocyst outgrowths. Blastocyst outgrowths were immunostained with rabbit non-specific IgG (A) or a rabbit anti-mouse MMP-2 antibody (B and C). Nuclei were counterstained with DAPI (blue). Immunoreactivity of MMP-2 was mainly detected in cytoplasm of trophoblast cells (red). Scale bars, $25 \mu \mathrm{m}$. 


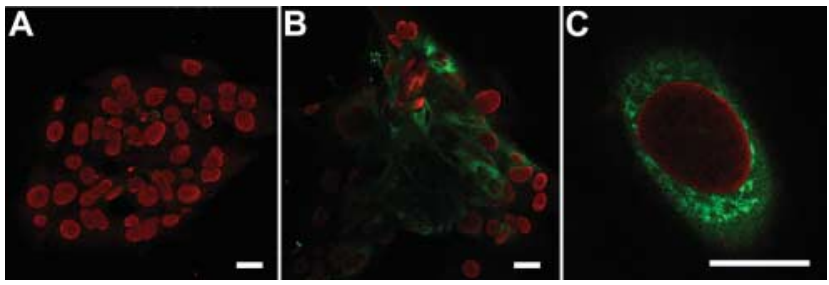

Figure 5 Expression of MMP-9 protein in mouse blastocyst outgrowths Blastocyst outgrowths were immunostained with rabbit non-specific IgG (A) or a rabbit anti-mouse MMP-9 antibody (B and C). Nuclei were counterstained with propidium iodide (red). MMP-9 was mainly detected in cytoplasm of trophoblast cells (green). Scale bars, $25 \mu \mathrm{m}$.

mouse trophoblast giant cells at the feto-maternal interface on day 8.5 of gestation (Balbin et al. 2001). The mRNAs for Mcol-A and -B were detectable in mouse embryos up to day 11.5 of gestation but not thereafter

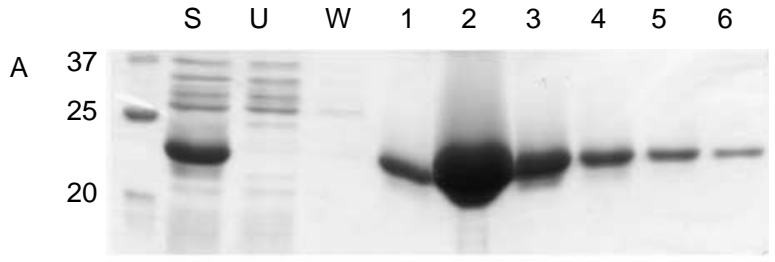

$\begin{array}{lllllllll}\mathrm{S} & \mathrm{U} & \mathrm{W} & 1 & 2 & 3 & 4 & 5 & 6\end{array}$
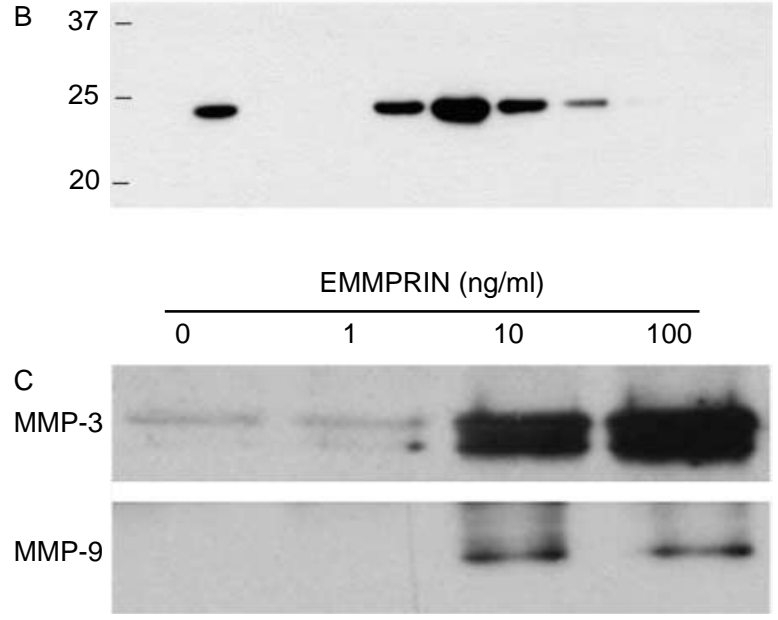

Figure 6 Purification and characterization of recombinant EMMPRIN protein. (A) Coomassie stained 10\% SDS-PAGE of fractions from the purification of recombinant EMMPRIN protein from an osmotic shock lysate. S, starting material; U, unbound fraction; W, Wash fraction, 1-6, protein fraction eluted with imidazole. The reduced protein resolves at the expected mass of $23 \mathrm{kDa}$. (B) Immunoblot analysis of the purified recombinant EMMPRIN using a goat anti-human EMMPRIN polyclonal antibody. The samples in A were diluted 25-fold, resolved by SDS-PAGE and immunoblotted with the anti-human EMMPRIN polyclonal antibody. Molecular mass standards (in $\mathrm{kDa}$ ) are indicated on the left of each figure. (C) Recombinant EMMPRIN stimulates MMP-3 and -9 protein secretion by mouse uterine stromal cells. Mouse stromal cells were isolated from pseudopregnant mouse uteri and treated with recombinant EMMPRIN protein at $0,1,10$, or $100 \mathrm{ng} / \mathrm{ml}$ for $24 \mathrm{~h}$. Conditioned media were concentrated and subjected to immunoblotting for MMP-3 and -9 .
(Balbin et al. 2001). In the present study, we found that the expression of Mcol-A and -B mRNA was first detected in the blastocyst outgrowths, which correspond to approximately day 5.5 or 6.5 of gestation. Our results indicate that the expression of Mcol-A and -B mRNAs in developing mouse embryos begins earlier than previously reported and is restricted to a specific period during pregnancy. Invasion of the blastocyst into the decidua is preceded by the attachment of the blastocyst to the uterine epithelium, which occurs at midnight of day 4 , and this invasive process ceases by day 10.5 . Therefore, the expression pattern of Mcol-A and -B suggests that these two proteinases may be involved in mouse embryo implantation. However, mRNAs for the other collagenases, MMP-8 and -13, were not detected in mouse blastocyst outgrowths in our study.

In this study, we detected only MMP-2 mRNA in blastocysts that underwent outgrowth for $72 \mathrm{~h}$. The expression of MMP-2 by mouse blastocysts is much lower compared with MMP-9 expression (Sharkey et al. 1996). We detected a very strong MMP-9 activity of blastocyst outgrowth by gelatin zymography, but we did not detect MMP-2 activity (Fig. 7B). Studies by Sharkey et al. (1996) demonstrated a very low level of MMP-2 mRNA in blastocysts that outgrew $24 \mathrm{~h}$ (Table 4). This slight difference of MMP-2 expression between Sharkey's studies and our studies may be due to the different number of blastocyst used for RT-PCR analysis. In the present study, we used only 10 blastocysts, whereas Sharkey et al. (1996) used 60 blastocysts. Studies by Wang et al. (2003) have shown the MMP-2 mRNA is expressed by all pre-implantation embryos from one-cell to blastocyst stage (Table 4). This different expression profile of MMP-2 could also be species-specific.

EMMPRIN has a demonstrated role in the induction of MMPs in a variety of cell types (Muramatsu \& Miyauchi 2003). Our data indicate that EMMPRIN mRNA and protein were expressed at all stages of pre-implantation development and certainly earlier than the expression of any of the MMPs. The lack of MMP expression in the preimplantation embryos when EMMPRIN is already expressed suggests that EMMPRIN may not function as a MMP inducer in embryos. The results from quantitative RT-PCR of embryos treated with recombinant EMMPRIN demonstrated that EMMPRIN did not stimulate either MMP-2 or -9 mRNA levels in blastocysts. Additionally, gelatin zymography studies indicated that EMMPRIN protein did not increase MMP-9 protein activity of blastocysts. The inability of the periplasmically expressed recombinant EMMPRIN protein to induce MMP-2 and -9 is not related to its inherent biological activity. In separate studies, we have found that this recombinant human EMMPRIN protein can induce MMP-3 and -9 expression by mouse uterine fibroblasts. Therefore, our results suggest that EMMPRIN may have a function other than stimulation of MMP expression in mouse embryos. Other functions for EMMPRIN include 

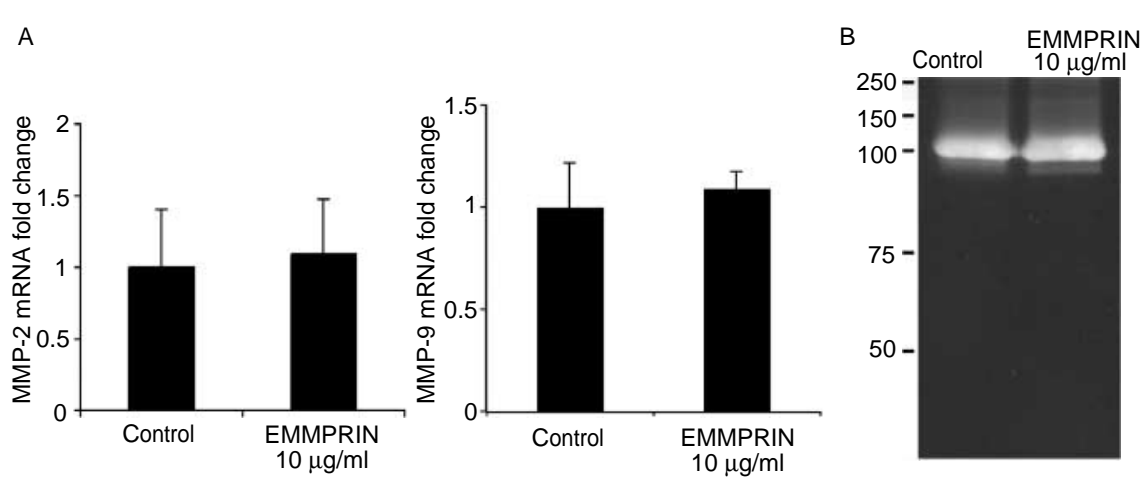

Figure 7 Recombinant EMMPRIN protein does not stimulate MMP-2 or -9 mRNA levels or protein activities in mouse blastocysts. Blastocyst outgrowths were treated with $10 \mu \mathrm{g} / \mathrm{ml}$ EMMPRIN protein for $24 \mathrm{~h}$. (A) Isolated mRNAs were subjected to quantitative RT-PCR for MMP-2 and -9. There was no significant difference between the control group and the EMMPRIN-treated group. Data represent the means from four independent experiments (means \pm s.E.). (B) Conditioned media were subjected to gelatin zymography. Clearing of the gelatin substrate (white bands) indicates MMP-9 activity. Lane 1, control samples; lane 2, treated with $10 \mu \mathrm{g} / \mathrm{ml}$ recombinant EMMPRIN.

a role in cell attachment, as EMMPRIN is known to interact with both the $\alpha 3 \beta 1$ and $\alpha 6 \beta 1$ integrins (Berditchevski et al. 1997), as well as a role in integrindependent morphogenesis of extraembryonic membranes and maintenance of cellular architecture in Drosophila (Reed et al. 2004, Curtin et al. 2005)

EMMPRIN is also known to function as a chaperone molecule for the proper targeting of the monocarboxylate transporter-1 (MCT1) in the cell membrane (Kirk et al. 2000). Monocarboxylate transporters are widely expressed on the cell surface and are necessary for the transport of monocarboxylates (e.g. lactate) across the plasma membrane in a number of tissues (Garcia et al. 1994, Halestrap \& Price 1999). Recent work has demonstrated that EMMPRIN colocalizes with MCTs in isolated heart cells and epithelial cells of the thyroid and retina (Kirk et al. 2000, Wilson et al. 2002, Fanelli et al.
2003). In the retinal pigment epithelia, EMMPRIN acts as a chaperone to directly regulate polarized expression of MCT1 and 3 to the apical and basolateral cell membranes respectively (Deora et al. 2004). In addition, expression of MCT1 was perturbed in several tissues of EMMPRIN null mutant mice, including skeletal muscle, cardiac muscle, liver, testis, and kidney (Nakai et al. 2006). It has been shown that MCT1, 2 and 4 are expressed by mouse embryos at all stages from two-cell to blastocyst (Herubel et al. 2002). Thus, one potentially important role for EMMPRIN in the mouse embryo could be the regulation of MCT localization and activity.

In conclusion, we have shown that peri-implantation mouse embryos express not only MMP-2 and -9 , but also Mcol-A and -B. These MMPs are not expressed until the embryo develops to an expanded blastocyst or is actually beginning to undergo outgrowth. EMMPRIN mRNA and

Table 3 Comparison of our present results for MMP-9 expression by developing mouse embryos with other previously published studies.

\begin{tabular}{|c|c|c|c|c|c|c|c|c|c|c|}
\hline & Species & One-cell & Two-cell & Four-cell & Eight-cell & Morula & BL & OG $24 \mathrm{~h}$ & OG $48 \mathrm{~h}$ & OG $72 \mathrm{~h}$ \\
\hline Our results & Mouse & - & - & - & - & - & + & ND & + & + \\
\hline Kim et al. (2002) & Mouse & ND & ND & ND & ND & ND & + & ND & + & ND \\
\hline Sharkey et al. (1996) & Mouse & ND & ND & ND & ND & ND & ND & + & ND & ND \\
\hline Whiteside et al. (2001) & Mouse & ND & ND & ND & ND & ND & ND & ND & ND & + \\
\hline
\end{tabular}

BL, blastocyst; OG 24 h, blastocyst outgrowth for 24 h; OG 48 h, blastocyst outgrowth for 48 h; OG 72 h, blastocyst outgrowth for 72 h. -, Negative; +, positive; ND, not determined.

Table 4 Comparison of our present results for MMP-2 expression by developing mouse embryos with other previously published studies.

\begin{tabular}{llccccccccc}
\hline & Species & One-cell & Two-cell & Four-cell & Eight-cell & Morula & BL & OG $24 \mathrm{~h}$ & OG $48 \mathrm{~h}$ & OG $72 \mathrm{~h}$ \\
\hline Our results & Mouse & - & - & - & - & - & - & ND & - & + \\
Kim et al. (2002) & Mouse & ND & ND & ND & ND & ND & ND & ND & ND & + \\
Sharkey et al. (1996) & Mouse & ND & ND & ND & ND & ND & ND & + & ND & ND \\
Whiteside et al. (2001) & Mouse & ND & ND & ND & ND & ND & ND & ND & ND & + \\
Wang et al. (2003) & Human & + & + & + & + & + & + & ND & ND & ND
\end{tabular}

BL, blastocyst; OG $24 \mathrm{~h}$, blastocyst outgrowth for $24 \mathrm{~h}$; OG $48 \mathrm{~h}$, blastocyst outgrowth for $48 \mathrm{~h}$; OG $72 \mathrm{~h}$, blastocyst outgrowth for $72 \mathrm{~h}$. - , negative; +, positive; ND, not determined. 
protein are present beginning at the one-cell zygote stage, but the expression of EMMPRIN does not appear to have a direct role in the induction of embryonic MMPs. Taken together, our data suggests that MMP expression during early embryonic development is regulated by a mechanism independent of EMMPRIN.

\section{Acknowledgements}

The authors would like to thank Dr G T Erbach for his technical expertise in the collection and staining of mouse embryos. This work was supported by the funding from NIH U54 HD40093 (RAN). The authors declare that there is no conflict of interest that would prejudice the impartiality of this scientific work.

\section{References}

Balbin M, Fueyo A, Knauper V, Lopez JM, Alvarez J, Sanchez LM, Quesada V, Bordallo J, Murphy G \& Lopez-Otin C 2001 Identification and enzymatic characterization of two diverging murine counterparts of human interstitial collagenase (MMP-1) expressed at sites of embryo implantation. Journal of Biological Chemistry 276 10253-10262.

Behrendtsen O, Alexander CM \& Werb Z 1992 Metalloproteinases mediate extracellular matrix degradation by cells from mouse blastocyst outgrowths. Development 114 447-456.

Berditchevski F, Chang S, Bodorova J \& Hemler ME 1997 Generation of monoclonal antibodies to integrin-associated proteins. Evidence that alpha3beta1 complexes with EMMPRIN/basigin/OX47/M6. Journal of Biological Chemistry 272 29174-29180.

Cross JC, Werb Z \& Fisher SJ 1994 Implantation and the placenta: key pieces of the development puzzle. Science 266 1508-1518.

Curry TE Jr \& Osteen KG 2003 The matrix metalloproteinase system: changes, regulation, and impact throughout the ovarian and uterine reproductive cycle. Endocrine Reviews 24 428-465.

Curtin KD, Meinertzhagen IA \& Wyman RJ 2005 Basigin (EMM$\mathrm{PRIN} / \mathrm{CD} 147$ ) interacts with integrin to affect cellular architecture. Journal of Cell Science 118 2649-2660.

Daikoku T, Tranguch S, Friedman DB, Das SK, Smith DF \& Dey SK 2005 Proteomic analysis identifies immunophilin FK506 binding protein 4 (FKBP52) as a downstream target of Hoxa10 in the periimplantation mouse uterus. Molecular Endocrinology 19 683-697.

Deora AA, Gravotta D, Kreitzer G, Hu J, Bok D \& Rodriguez-Boulan E 2004 The basolateral targeting signal of CD147 (EMMPRIN) consists of a single leucine and is not recognized by retinal pigment epithelium. Molecular Biology of the Cell 15 4148-4165.

Fanelli A, Grollman EF, Wang D \& Philp NJ 2003 MCT1 and its accessory protein CD147 are differentially regulated by TSH in rat thyroid cells. American Journal of Physiology. Endocrinology and Metabolism 285 E1223-E1229.

Garcia CK, Goldstein JL, Pathak RK, Anderson RG \& Brown MS 1994 Molecular characterization of a membrane transporter for lactate, pyruvate, and other monocarboxylates: implications for the Cori cycle. Cell 76 865-873.

Guo H, Majmudar G, Jensen TC, Biswas C, Toole BP \& Gordon MK 1998 Characterization of the gene for human EMMPRIN, a tumor cell surface inducer of matrix metalloproteinases. Gene 220 99-108.

Halestrap AP \& Price NT 1999 The proton-linked monocarboxylate transporter (MCT) family: structure, function and regulation. Biochemical Journal 343 Pt 2 281-299.
Herubel F, El Mouatassim S, Guerin P, Frydman R \& Menezo Y 2002 Genetic expression of monocarboxylate transporters during human and murine oocyte maturation and early embryonic development. Zygote 10 175-181.

Igakura T, Kadomatsu K, Kaname T, Muramatsu H, Fan QW, Miyauchi T, Toyama Y, Kuno N, Yuasa S, Takahashi M et al. 1998 A null mutation in basigin, an immunoglobulin superfamily member, indicates its important roles in peri-implantation development and spermatogenesis. Developmental Biology 194 152-165.

Kanekura T, Chen X \& Kanzaki T 2002 Basigin (CD147) is expressed on melanoma cells and induces tumor cell invasion by stimulating production of matrix metalloproteinases by fibroblasts. International Journal of Cancer 99 520-528.

Kataoka H, DeCastro R, Zucker S \& Biswas C 1993 Tumor cell-derived collagenase-stimulatory factor increases expression of interstitial collagenase, stromelysin, and 72-kDa gelatinase. Cancer Research 53 3154-3158.

Kim JH, Hong SH, Nah HY, Lee JY, Chae HD, Kim CH, Kang BM \& Bae IH 2002 Influence of transforming growth factor-alpha on expression of matrix metalloproteinase-2, matrix metalloproteinase9, and epidermal growth factor receptor gene in the mouse blastocysts. Journal of Assisted Reproduction and Genetics 19 232-239.

Kirk P, Wilson MC, Heddle C, Brown MH, Barclay AN \& Halestrap AP 2000 CD147 is tightly associated with lactate transporters MCT1 and MCT4 and facilitates their cell surface expression. EMBO Journal 19 3896-3904

Li R, Huang L, Guo H \& Toole BP 2001 Basigin (murine EMMPRIN) stimulates matrix metalloproteinase production by fibroblasts. Journal of Cellular Physiology 186 371-379.

Lim M, Martinez T, Jablons D, Cameron R, Guo H, Toole B, Li JD \& Basbaum C 1998 Tumor-derived EMMPRIN (extracellular matrix metalloproteinase inducer) stimulates collagenase transcription through MAPK p38. FEBS Letters 441 88-92.

Muramatsu T \& Miyauchi T 2003 Basigin (CD147): a multifunctional transmembrane protein involved in reproduction, neural function, inflammation and tumor invasion. Histology and Histopathology 18 981-987.

Nakai M, Chen L \& Nowak RA 2006 Tissue distribution of basigin and monocarboxylate transporter 1 in the adult male mouse: a study using the wild-type and basigin gene knockout mice. Anatomical Record. Part A, Discoveries in Molecular, Cellular, and Evolutionary Biology 288 527-535.

Nowak RA, Haimovici F, Biggers JD \& Erbach GT 1999 Transforming growth factor-beta stimulates mouse blastocyst outgrowth through a mechanism involving parathyroid hormone-related protein. Biology of Reproduction 60 85-93.

Paria BC, Reese J, Das SK \& Dey SK 2002 Deciphering the cross-talk of implantation: advances and challenges. Science 296 2185-2188.

Reed BH, Wilk R, Schock F \& Lipshitz HD 2004 Integrin-dependent apposition of drosophila extraembryonic membranes promotes morphogenesis and prevents anoikis. Current Biology 14 372-380.

Sameshima T, Nabeshima K, Toole BP, Yokogami K, Okada Y, Goya T, Koono M \& Wakisaka S 2000 Glioma cell extracellular matrix metalloproteinase inducer (EMMPRIN) (CD147) stimulates production of membrane-type matrix metalloproteinases and activated gelatinase $\mathrm{A}$ in co-cultures with brain-derived fibroblasts. Cancer Letters 157 177-184.

Sharkey ME, Adler RR, Nieder GL \& Brenner CA 1996 Matrix metalloproteinase expression during mouse peri-implantation development. American Journal of Reproductive Immunology 36 $72-80$.

Sun J \& Hemler ME 2001 Regulation of MMP-1 and MMP-2 production through CD147/extracellular matrix metalloproteinase inducer interactions. Cancer Research 61 2276-2281.

Vu TH, Shipley JM, Bergers G, Berger JE, Helms JA, Hanahan D, Shapiro SD, Senior RM \& Werb Z 1998 MMP-9/gelatinase B is a key regulator of growth plate angiogenesis and apoptosis of hypertrophic chondrocytes. Cell 93 411-422. 
Whiteside EJ, Jackson MM, Herington AC, Edwards DR \& Harvey MB 2001 Matrix metalloproteinase-9 and tissue inhibitor of metalloproteinase-3 are key regulators of extracellular matrix degradation by mouse embryos. Biology of Reproduction 64 1331-1337.

Wilson MC, Meredith D \& Halestrap AP 2002 Fluorescence resonance energy transfer studies on the interaction between the lactate transporter MCT1 and CD147 provide information on the topology and stoichiometry of the complex in situ. Journal of Biological Chemistry 277 3666-3672.

Yang JM, Xu Z, Wu H, Zhu H, Wu X \& Hait WN 2003 Overexpression of extracellular matrix metalloproteinase inducer in multidrug resistant cancer cells. Molecular Cancer Research 1 420-427.
Zucker S, Hymowitz M, Rollo EE, Mann R, Conner CE, Cao J, Foda HD, Tompkins DC \& Toole BP 2001 Tumorigenic potential of extracellular matrix metalloproteinase inducer. American Journal of Pathology 158 1921-1928.

Received 1 November 2005

First decision 28 November 2005

Revised manuscript received 18 November 2006 Accepted 29 November 2006 